\title{
Ciclotídeos e suas principais estruturas moleculares e espécimes: uma revisão de
}

\section{literatura}

\author{
Cyclotides and their main molecular structures and specimens: a literature review \\ Ciclotides y sus principales estructuras moleculares y especímenes: una revisión de la literatura
}

Dalton Ferreira Matos

ORCID: https://orcid.org/0000-0002-6188-7536 Universidade Federal de Sergipe, Brasil E-mail: daltonmatosgn@gmail.com

Wandklebson Silva da Paz

ORCID: https://orcid.org/0000-0002-2898-2646

Universidade Federal de Pernambuco, Brasil E-mail: wandklebson.paz@gmail.com

Quezia Machado dos Santos Araújo ORCID: https://orcid.org/0000-0002-0871-3334 Universidade Estadual de Alagoas, Brasil E-mail: qmsabio@gmail.com

Mikaelle Alves Silva

ORCID: https://orcid.org/0000-0002-9336-1491 Universidade Federal do Espírito Santo, Brasil E-mail: farm.mikaelle@gmail.com

Mayane Luiza Alves Nunes

ORCID: https://orcid.org/0000-0002-2646-8707 Universidade Estadual de Alagoas, Brasil

E-mail: maayanenunes@gmail.com

Rafael dos Santos Balbino

ORCID: https://orcid.org/0000-0001-6375-2021 Instituto Federal de Alagoas, Brasil

E-mail: rafael.balbino@ifal.edu.br

Allan Bruno Alves de Sousa Santos

ORCID: https://orcid.org/0000-0001-6412-7164

Faculdade de Educação São Francisco, Brasil E-mail: abass@ faesf.com.br

André Cardoso Tavares

ORCID: https://orcid.org/0000-0002-8413-3868 Centro Universitário UNIFACID-WYDEM, Brasil E-mail: andrebiomed16@gmail.com

Juniel Marques de Oliveira

ORCID: https://orcid.org/0000-0002-0557-6872 Instituição: Universidade Estadual do Piauí, Brasil E-mail: junielmrqs.88@gmail.com

Jansiel Pereira Barbosa

ORCID: https://orcid.org/0000-0002-7313-1314 Centro Universitário Maurício de Nassau, Brasil E-mail: pereirajansiel@gmail.com

Luciano Jorge dos Santos Júnior ORCID: https://orcid.org/0000-0001-5766-3874 Universidade Federal de Sergipe, Brasil E-mail: lucianojorge@ outlook.com

Joyce Francielle Ferreira Santos ORCID: https://orcid.org/0000-0002-7364-8858 Universidade Federal de Sergipe, Brasil E-mail: joyce.conexao@gmail.com

\section{Resumo}

Assim como as proteínas, os peptídeos apresentam uma variedade de funções como, por exemplo: função estrutural, reserva energética, transporte, enzimática, hormonal e até mesmo na defesa dos organismos contra corpos estranhos. Como por exemplo os ciclotídeos que são uma classe de peptídeos que possuem uma cadeia fechada, que acabam se diferenciando dos demais peptídeos graças à conformação circular diferente de outras estruturas de peptídeos que são lineares, desempenhando função imunológica em espécies vegetais. Além do mais esse grupo de peptídeos possui uma 
ampla distribuição, sendo que atualmente existem cerca de 50 ciclotídeos distribuídos em 5 famílias de plantas superiores: Rubiaceae, Solanaceae, Fabaceae, Cucurbitaceae e Violaceae, sendo que a maior distribuição se encontra na família das Violaceae. Na literatura cientifica existem poucos trabalhos que retratem de forma aprofundada sobre esse grupo de peptídeos, por conseguinte este trabalho tem como objetivo retratar a biossíntese, principais espécimes, como também as principais estruturas moleculares dos ciclotídeos.

Palavras-chave: Química; Plantas; Biossíntese.

\begin{abstract}
As proteins, peptides have a variety of functions, such as structural function, energy reserve, transport, enzymatic, hormonal, and even in the defense of organisms against foreign bodies. As for example the cyclotides, which are a class of peptides that have a closed chain, which end up differentiating themselves from other peptides thanks to the circular conformation different from other peptide structures that are linear, performing an immunological function in plant species. Moreover, this group of peptides has a wide distribution, and currently there are about 50 cyclotides distributed in 5 families of higher plants: Rubiaceae, Solanaceae, Fabaceae, Cucurbitaceae and Violaceae, with the largest distribution is in the family of Violaceae. In the scientific literature there are few studies that portray in depth this group of peptides, therefore this work aims to portray the biosynthesis, main specimens, as well as the main molecular structures of cyclotides.
\end{abstract}

Keywords: Chemistry; Plants; Biosynthesis.

\title{
Resumen
}

Al igual que las proteínas, los péptidos tienen una variedad de funciones como la función estructural, la reserva de energía, el transporte, enzimático, hormonal e incluso en la defensa de los organismos contra cuerpos extraños. Como por ejemplo los ciclopéptidos que son una clase de péptidos que tienen una cadena cerrada, que acaban diferenciándose de otros péptidos gracias a la diferente conformación circular de otras estructuras peptídicas que son lineales, realizando la función inmune en especies vegetales. Además, este grupo de péptidos tiene una amplia distribución, y actualmente existen unos 50 ciclotides distribuidos en 5 familias de plantas superiores: Rubiaceae, Solanaceae, Fabaceae, Cucurbitaceae y Violaceae, y la mayor distribución se encuentra en la familia de Violaceae. En la literatura científica existen pocos estudios que retraten en profundidad sobre este grupo de péptidos, por lo que este trabajo tiene como objetivo retratar la biosíntesis, los principales especímenes, así como las principales estructuras moleculares de los ciclotides.

Palabras clave: Química; Plantas; Biosíntesis.

\section{Introdução}

Os peptídeos são biomoléculas que possuem de dois a dezenas de resíduos de aminoácidos unidos entre si através de ligações peptídicas. A cadeia peptídica é uma parte variável, que corresponde às distintas cadeias laterais, em que a cadeia principal é denominada de espinha dorsal ou arcabouço, sendo que a maioria das cadeias peptídicas contem entre 50 e 2.000 aminoácidos (Stryer, Tymoczko, Berg, 1996).

Assim como as proteínas, os peptídeos apresentam uma variedade de funções: função estrutural (Saadi et al., 2021), de reserva energética (Suyetin et al., 2021), transporte (Cross et al., 2021), enzimática (Rathnayake et al., 2021), hormonal (Albrechtsen, Rehfeld, 2021) e até mesmo na defesa dos organismos contra corpos estranhos (Martell et al., 2021). E, vale salientar que podem apresentar características importantes na defesa de um determinado organismo, os peptídeos antimicrobianos (PAM'S), que possuem atividade inibitória geral, ou seja, agem contra fungos, bactérias, parasitas ou vírus (Saiqali, Tangutur, Bhukya, 2021).

Os PAM'S são moléculas evolutivamente antigas, que atuam como componentes do sistema imunológico inato. Pesquisadores demostraram que um único PAM pode desempenhar várias funções, sendo essa capacidade conhecida como "promiscuidade de peptídeo". No entanto, pouco se sabe sobre a promiscuidade em plantas sem ligações dissulfeto (Silva et al., 2012).

Sabe-se que esse grupo de peptídeos participam do sistema imunológico montando uma primeira linha de defesa contra patógenos. Posteriormente, interage com o microrganismo alvo através dos receptores de membrana ou no próprio envoltório nuclear com a inserção do mesmo no citoplasma, resultando em prejuízos na função da membrana. É perceptível que essa estrutura é o principal determinante de sua ação, seja como alvo principal da ação do peptídeo, seja por formar uma 
barreira que deve ser cruzada para atingir as principais vias metabólicas. Assim, ocorre a morte celular por lise, mas a especificidade exibida pelos peptídeos antimicrobianos depende da composição lipídica diferente entre o patógeno e as células hospedeiras, provavelmente contribuindo para seu espectro de atividade (Teixeira, Feio, Bastos, 2012).

PAM's do tipo bacteriocinas são encontrados em vários espécimes, inclusive em vegetais, como as vicilinas ou as clavanina, mas existem um grupo de peptídeo bacteriano que é considerado peculiar: os ciclotídeos. Estes, compõem uma classe de peptídeos que possuem uma cadeia fechada e, se divergem das demais graças à conformação circular diferente de outras estruturas de peptídeos que são lineares (Malagón et al., 2013; Neves, 2018).

O primeiro ciclotídeo retratado na literatura cientifica foi o kalata B1, descrito no início da década de 1960 por um médico norueguês que ao observar uma tribo de codinome Lulula usava o extrato aquoso da espécie Oldenlandia affinis afim de utilizar o chá dessa planta com o intuito de facilitar durante o parto, pois esse chá possui características uterotônicas. Todavia, ao analisar com mais cautela, foi identificado estruturas cíclicas que posteriormente foram denominadas de Kalata B1, em função do nome popular da planta (Kalata kalata).

Esse grupo de peptídeo, apresentam cerca de 28 a 37 resíduos de aminoácidos. No entanto, existem divergências entre pesquisadores no que se trata do número de resíduos (Broussalis, Ferraro, 2006). Broussalis e Ferraro (2006) e Picchi et al (2009), relatam em seus trabalhos que ocorrem divergências no número desses resíduos e isso possa ocorrer porque os peptídeos cíclicos de maior tamanho possuíam cerca de 30 resíduos de aminoácidos. Na literatura cientifica não existem muitos trabalhos focados neste grupo de peptídeos. Por conseguinte, este estudo tem como objetivo retratar a biossíntese, principais espécimes, como também as principais estruturas moleculares dos Ciclotídeos.

\section{Metodologia}

\subsection{Tipo de Estudo}

Estudo descritivo de revisão bibliográfica.

\subsection{Procedimentos Metodológicos}

Foi estabelecido um modelo conceitual de hipóteses cuja temática desta pesquisa buscou avaliar sobre os ciclotídeos, juntamente de suas principais estruturas moleculares, biossíntese e distribuição em espécies que foram retratadas na literatura cientifica.

Esta pesquisa consistiu em uma revisão de literatura revistas indexadas em bancos de dados da PubMed, ScienceDirect, SciELO e Web of Science. Em que os artigos selecionados para a análise, cujo título, resumo ou até mesmo o corpo do texto apresentem descritores propostos pela biblioteca virtual em saúde nos idiomas português, inglês e espanhol: Visto que esses descritores que forão utilizados são: "Ciclotídeos" "Espécies", "Biossíntese" "Estruturas Moleculares", "Química".

Em seguida foi realizado a exclusão dos trabalhos artigos que não abordassem dados a respeito dos Ciclotídeos no contexto de uma visão bioquimica e molecular.

\subsection{Considerações Éticas}

Essa pesquisa envolveu apenas dados secundários pertencentes a literatura cientifica, por esse motivo não foi necessário ser encaminhado ao comitê de ética. 


\section{Biossíntese dos Ciclotídeos}

Deve-se levar em consideração que a síntese de aminoácidos depende das quantidades das enzimas de biossíntese e de suas atividades, pois os aminoácidos são considerados os blocos de construção de proteínas e peptídeos. Servindo de percussores de muitos tipos de moléculas pequenas que tem diversos papeis biológicos importantes (Stryer, Tymoczko, Berg, 1996).

Um exemplo é a biossíntese de peptídeos cíclicos naturais, no qual a maioria dos peptídeos são produzidos pelos ribossomos, que usam o RNA mensageiro (mRNA) como modelo e, em seguida, montam os aminoácidos para formar um peptídeo ou proteína.

No caso dos ciclotídeos, são proteínas cíclicas codificadas por genes e produzidas pelo ribossomo. Sua biossíntese é considerada um processo de várias etapas que envolvem enzimas para tradução, isomerização de dissulfeto, transporte, clivagem e finalmente a ciclização. As proteínas precursoras de ciclotídeo contêm predomínios que irão direcionar organelas que contenham sequências necessárias para ciclização, além de um ou mais domínios que constituem o produto cíclico final (Shafe, Harris, Anderson, 2015).

Segundo Craik e Malik (2013), ainda existem poucos trabalhos relacionados sobre a biossíntese desse grupo. No entanto, o que se sabe até o momento é que eles são codificados por genes expressos como proteínas precursoras e processados pós-tradução para produzir uma estrutura cíclica, sendo considerados a maior família de proteínas circulares, com mais de 250 sequências relatadas.

Mas, sabe-se que inicialmente segue uma reação de clivagem de protease de cisteína clássica envolvendo a formação de um intermediário de enzimas acila. Normalmente, este intermediário seria resolvido por hidrólise. Em contraste, no caso da produção de peptídeo cíclico, parece que o aminoácido N-terminal do precursor de ciclotídeo parcialmente processado é capaz de atuar como um nucleófilo e completar uma reação de ciclização em vez de hidrólise (Craik, Malik, 2013).

Outra coisa que se sabe é que existem um grupo de famílias de proteases de cisteína denominadas VPEs que realizam a ciclização por uma adaptação em seu mecanismo de proteólise, no qual a ciclização mediada por VPE é dependente da presença de sequências de reconhecimento curtas (dentro e flanqueando o domínio do ciclotídeo maduro) que foram caracterizadas in vivo e in vitro para o ciclotídeo prototípico Kalata B1 (Shafee, Harris, Anderson, 2015).

\section{Distribuição dos Ciclotídeos em Espécies de Plantas}

Atualmente existem cerca de 50 ciclotídeo distribuídos em 5 famílias de plantas superiores: Rubiaceae (Principal representante é o Café), Solanaceae (Principal representante é o_Tomate), Fabaceae (Leguminosas), Cucurbitaceae (Principal representante é a abóbora) e Violaceae (família das violetas) (Tabalea 1). Sendo que na família Violaceae os peptídeos macrocíclicos parecem estar presentes em todos os gêneros das espécies que foram estudados até o momento, como é o caso da espécie V. betonicifolia (Picchi et al., 2009; Rajendran et al., 2021). 
Tabela 1: Distribuição dos ciclotideos de acordo com as principais espécies de plantas.

\begin{tabular}{|c|c|c|c|}
\hline Espécie Vegetal & Família & Ciclotídeo & Referências \\
\hline Viola ignobilis & Violaceae & varv $\mathrm{A}, \mathrm{cyO} 8$, cyB2 & Hashempour et al. 2011 \\
\hline Viola abyssinica & Violaceae & vaby $A-E$ & Yeshak et al. 2011 \\
\hline Viola ignobilis & Violaceae & $\begin{array}{l}\text { vigno } 1-10, \text { cyO2, } \\
\text { cyO9 }\end{array}$ & Hashempour et al. 2013 \\
\hline Gloeospermum pauciflorum & Violaceae & glopa F-G & Burman et al. 2015 \\
\hline Viola tricolor & Violaceae & mela $1-7$ & Hallinger et al. 2015 \\
\hline Viola odorata & Violaceae & $\begin{array}{l}\text { VOL-2, VOP-4, } \\
\text { VOL-44, VOP-11, } \\
\text { VOP-17, cyO2, cyO3, } \\
\text { cyO13, cyO19. }\end{array}$ & $\begin{array}{l}\text { Dancewicz et al., 2020; } \\
\text { Narayani et al., } 2021\end{array}$ \\
\hline Hybanthus parviflorus & Violaceae & Нyра A & $\begin{array}{l}\text { Broussalis, Clemente, } \\
\text { Ferraro, } 2010\end{array}$ \\
\hline Oldenlandia affinis & Rubiaceae & Kalata B1, Kalata B2 & $\begin{array}{l}\text { Jennings et al., 2001; } \\
\text { Jennings et al., 2005; } \\
\text { Gupta, Mishra, Ghosh, } \\
2021\end{array}$ \\
\hline Chassalia chartacea & Rubiaceae & Chassatide $\mathrm{C} 1 / \mathrm{C} 4$ & Nguyen et al., 2012 \\
\hline Chassalia parvifolia & Rubiaceae & Circulin A & Tam et al., 1999 \\
\hline Chassalia ternatea & Fabaceae & Cliotide T1 & Nguyen et al., 2011 \\
\hline Psychotria longipes & Rubiaceae & Cyclopsychotride A & Nguyen et al., 2011 \\
\hline Melicytus latifolius & Violaceae & Mela 1 & Ravipati et al., 2015; \\
\hline Panicum laxum & Poaceae & Panitide L1 & Nguyen et al., 2013 \\
\hline
\end{tabular}

Fonte: Autores.

\section{Principais Estruturas e Funções dos Ciclotídeos}

Os ciclotídeos são proteínas vegetais divididas em 5 famílias, como foi retratado anteriormente, sendo ricos em dissulfeto que são excepcionais em sua estrutura cíclica, no qual seus terminais N e C são unidos por uma ligação peptídica (Burman et al., 2010). Possuindo cerca de 28 a 37 aminoácidos, por vezes ocorre divergência nesse número de aminoácidos.

Os ciclotídeos possuem um esqueleto cíclico, no qual possui um ciclo contínuo de ligações de peptídeos que compõem esse esqueleto. Eles contêm 6 resíduos de cisteína (Cis), formando 3 pontes de dissulfeto que estabilizam a molécula. Suas propriedades físicas incluem resistência à degradação térmica e enzimática, podem ser atribuídas ao seu esqueleto cíclico e pontes de dissulfeto que, ao formar o nó de arranjo estrutural da cistina cíclica, dão grande estabilidade à molécula (Broussalis, Ferraro et al., 2006). 
Segundo o trabalho de Daly, Rosengren e Craik (2009), os pesquisadores retratam que esse peptídeo são caracterizados pela fórmula ciclo-C ${ }^{\mathrm{I}}-\mathrm{X}_{a}-\mathrm{C}^{\mathrm{II}}-\mathrm{X}_{b}-\mathrm{C}^{\mathrm{III}}-\mathrm{X}_{c}-\mathrm{C}^{\mathrm{IV}}-\mathrm{X}_{d}-\mathrm{C}^{\mathrm{V}}-\mathrm{X}_{e}-\mathrm{C}^{\mathrm{IV}}-\mathrm{X}_{f}$, onde os (X) representam os aminoácidos de cisteína, (a) corresponde a 3-6 desses resíduos, (b) corresponde a 4-8 resíduos, $(c)$ a 3-7 resíduos, $(d)$ é um único aminoácido, (e) está no intervalo de 4-5 resíduos (ef) está no intervalo de 5-8 resíduos. Dado que todos os ciclotídeos têm uma estrutura topologicamente circular e seis cisteínas em que existem seis segmentos, ou loops, na estrutura entre os resíduos de cisteína, que são sucessivamente numerados de 1 a 6 , começando na cisteína 1 .

Os ciclotídeos mostram uma gama diversificada de bioatividades, incluindo antimicrobiana, citotóxica, anti-HIV, inseticida e atividades uterotônicas (Rajendran et al., 2021). Possuindo uma diversidade de ciclotideos como foi demonstrado na Tabela 1. Todavia, vale destacar 3 estruturas como foi retratado no trabalho de Rajendran et al., (2021), em que os pesquisadores retrataram sobre Kalata B1, Cycloviolacin O2, e MCoTI-II. O ciclotídeo Kalata B1, demonstrou que a interação dessa estrutura com os fosfolipídios, são consideradas fracamente ativa, o que acaba afetando a interação entre moléculas de lipídeos espalhadas na interface ar-águas (Gupta, Mishra, Ghosh, 2021).

\section{Conclusão}

Os ciclotídeos possuem várias atividades biológicas como uterotônica, antimicrobiana, anti-helmíntica, moluscicidas, antitumoral, entre outros, mostrando grande importância, além de ter uma ampla distribuição em diversas espécies, sendo que o grupo que possui a maior distribuição é a família das Violaceae. No entanto, deve-se levar em consideração que é necessário estudos mais aprofundados a respeito de sua biossíntese e atividade biológica em outras espécies que ainda não tenham estudos de acordo com a literatura cientifica. Assim, futuramente, podem ser usados como uma das alternativas em estudos voltados para bactérias resistentes a fármacos ou até mesmo em estudos voltados para a síndrome da imunodeficiência adquirida.

\section{Referências}

Albrechtsen, N. J. W; Rehfeld, J. F. On Premises and Principles for Measurement of Gastrointestinal Peptide Hormones. Peptides, p. $170545,2021$.

Broussalis, A. M; Ferraro, G. E. Ciclótidos: péptidos macrocíclicos presentes en plantas (Revisión). Dominguezia, v. 22, n. 1, p. 7-14, 2006.

Broussalis, A. M; Clemente, S; Ferraro, G. E. Hybanthus parviflorus (Violaceae): Insecticidal activity of a South American plant. Crop Protection, v. 29, n. 9, p. $953-956,2010$.

Burman, R. et al. Distribution of circular proteins in plants: large-scale mapping of cyclotides in the Violaceae. Front. Plant. Sci., v. 6, p. 855, 2015.

Craik, D. J; Malik, U. Cyclotide biosynthesis. Current opinion in chemical biology, v. 17, n. 4, p. 546-554, 2013.

Cross, J A. et al. Fragment-linking peptide design yields a high-affinity ligand for microtubule-based transport. Cell Chemical Biology, 2021.

Daly, N. L; Rosengren, K. J; Craik, D. J. Discovery, structure and biological activities of cyclotides. Advanced drug delivery reviews, v. 61, n. 11, p. 918-930, 2009.

Dancewicz, K et al. Behavioral and physiological effects of Viola spp. cyclotides on Myzus persicae (Sulz.). Journal of insect physiology, v. 122, p. 104025, 2020 .

Gupta, R; Mishra, M; Ghosh, S. K. Interaction of cyclotide Kalata B1 protein with model cellular membranes of varied electrostatics. International Journal of Biological Macromolecules, 2021.

Hashempour, H. et al. Analysis of cyclotides in Viola ignobilis by nano liquid chromatography fourier transform mass spectrometry. Prot. Pept. Lett., v. 18, p. 747- 752, 2011.

Hashempour, H. et al. Characterizing circular peptides in mixtures: sequence fragment assembly of cyclotides from a violet plant by MALDI-TOF/TOF mass spectrometry. Amino Acids, v. 44, p. 581-595, 2013.

Hellinger, R. et al. Peptidomics of circular cysteine-rich plant peptides: analysis of the diversity of cyclotides from Viola tricolor by transcriptome and proteome mining. J. Proteome Res., v. 14, p. 4851-4862, 2015.

https://www.netinbag.com/pt/science/what-is-a-cyclic-peptide.html. 
Jennings, C et al. Biosynthesis and insecticidal properties of plant cyclotides: the cyclic knotted proteins from Oldenlandia affinis. Proceedings of the National Academy of Sciences, v. 98, n. 19, p. 10614-10619, 2001.

Jennings, C. V. et al. Isolation, solution structure, and insecticidal activity of kalata B2, a circular protein with a twist: do Möbius strips exist in nature?. Biochemistry, v. 44, n. 3, p. 851-860, 2005.

Malagón, D et al. Anthelminthic activity of the cyclotides (kalata B1 and B2) against schistosome parasites. Peptide Science, v. 100, n. 5, p. 461-470, 2013.

Martell, Ernesto M. et al. Host defense peptides as immunomodulators: The other side of the coin. Peptides, v. 146, p. 170644, 2021.

Nguyen, G. K. T et al. Discovery and characterization of novel cyclotides originated from chimeric precursors consisting of albumin-1 chain a and cyclotide domains in the Fabaceae family. Journal of Biological Chemistry, v. 286, n. 27, p. 24275-24287, 2011.

Nguyen, G, K. T et al. Novel cyclotides and uncyclotides with highly shortened precursors from Chassalia chartacea and effects of methionine oxidation on bioactivities. Journal of Biological Chemistry, v. 287, n. 21, p. 17598-17607, 2012.

Nguyen, G. K. T et al. Discovery of linear cyclotides in monocot plant Panicum laxum of Poaceae family provides new insights into evolution and distribution of cyclotides in plants. Journal of Biological Chemistry, v. 288, n. 5, p. 3370-3380, 2013.

Narayani, M. et al. Production of bioactive cyclotides in somatic embryos of Viola odorata. Phytochemistry, v. 156, p. 135-141, 2018

Neves, N. C. Ciclotídeos: origem, estrutura e funções secundárias, uma revisão narrativa. 2018.

Picchi, D. G et al. Peptídeos cíclicos de biomassa vegetal: características, diversidade, biossíntese e atividades biológicas. Química Nova, v. 32, p. 1262-1277, 2009.

Ravipati, A. S. et al. Lysine-rich cyclotides: a new subclass of circular knotted proteins from violaceae. ACS chemical biology, v. 10, n. 11, p. 2491-2500, 2015 .

Rajendran, S et al. Tropical vibes from Sri Lanka-cyclotides from Viola betonicifolia by transcriptome and mass spectrometry analysis. Phytochemistry, v. 187 , p. $112749,2021$.

Rathnayake, A. U et al. Characterization and Purification of $\beta$ - Secretase Inhibitory Peptides Fraction from Sea Cucumber (Holothuria spinifera) Enzymatic Hydrolysates. Process Biochemistry, 2021.

Stryer, L; Tymoczko, J. L; Berg, J. M. Bioquímica; $4^{\text {a }}$ Edição. Editora

Guanabara, 1996.

Silva, O. N. et al. Cn-AMP1: A new promiscuous peptide with potential for microbial infections treatment. Peptide Science, v. 98 , n. 4, p. 322-331, 2012.

Shafee, T; Harris, K; Anderson, M. Biosynthesis of cyclotides. Advances in Botanical Research, v. 76, p. $227-269,2015$.

Silva, O. N. et al. Cn-AMP1: A new promiscuous peptide with potential for microbial infections treatment. Peptide Science, v. 98, n. 4, p. 322-331, 2012.

Saadi, S et al. The structural reconformation of peptides in enhancing functional and therapeutic properties: Insights into their solid state crystallizations. Biophysical Chemistry, p. 106565, 2021.

Saiqali, A. M; Tangutur, A. D; Bhukya, B. Peptides and low molecular weight polypeptides of Azadirachta indica seeds as new weapons against cancer cells and superbugs. Phytomedicine Plus, p. 100118, 2021.

Suyetin, M et al. Modelling peptide adsorption energies on gold surfaces with an effective implicit solvent and surface model. Journal of Colloid and Interface Science, v. 605, p. 493-499, 2021.

Tam, J. P. et al. An unusual structural motif of antimicrobial peptides containing end-to-end macrocycle and cystine-knot disulfides. Proceedings of the National Academy of Sciences, v. 96, n. 16, p. 8913-8918, 1999.

Teixeira, V; Feio, M. J.; Bastos, M. Role of lipids in the interaction of antimicrobial peptides with membranes. Progress in lipid research, v. 51, n. 2, p. 149$177,2012$.

Yeshak, M. Y. et al. Cyclotides from an extreme habitat: characterization of cyclic peptides from Viola abyssinica of the Ethiopian highlands. J. Nat. Prod., v. 74, p. 727- 731, 2011. 